\title{
METODOLOGIA PARA AVALIAÇÃO DO POTENCIAL ESTÉTICO DAS GEOFORMAS NA ÁREA DO PROJETO GEOPARQUE CARIRI PARAIBANO
}

\section{MEHODOLOGY FOR THE ASSESSMENT THE AESTHETIC POTENTIAL OF GEOFORMS IN THE CARIRI PARAIBANO GEOPARK PROJECT}

\author{
Carla Soares Borba \\ carlasborba@gmail.com \\ Leonardo Figueiredo de Meneses ${ }^{1}$ \\ Ifmeneses@hotmail.com
}

\begin{abstract}
This work presents a proposal of evaluation of the aesthetic/touristic potential of the geoforms through the perception of their similarity when compared to daily images and associated values, with the purpose of fostering geodiversity through tourism. The area covered by this study includes the borders of the Cariri Paraibano Geopark Project, in the municipalities of Boa Vista, Boqueirão, Cabaceiras and São João do Cariri, all of which are located in the Cariris Velhos region of Paraíba State. This research was based on the review of specialized literature, in order to assess the available methodologies aimed at the evaluation of the geoheritage as well as on the creation of an evaluation/quantification record to identify the aesthetic, scientific and use potential, and need for protection of the geoforms. As a result, an evaluation of 15 geoforms was carried out, focusing on those that presented the highest aesthetic potential to elaborate the tourist/routes in the geopark's area.
\end{abstract}

Keywords: Geodiversity, Tourism, Inventory.

\footnotetext{
${ }^{1}$ Docente, DEMA/UFPB.
} 


\section{RESUMO}

Este trabalho apresenta uma proposta de avaliação do potencial estético/turístico das geoformas por meio da percepção de sua semelhança com imagens cotidianas e de valores associados, a fim de divulgar a geodiversidade por meio do turismo. A área de estudo abrange os limites do Projeto Geoparque Cariri Paraibano, do qual fazem parte os municípios de Boa Vista, Boqueirão, Cabaceiras e São João do Cariri, todos localizados nos Cariris Velhos da Paraíba. A metodologia da pesquisa se baseou em uma revisão bibliográfica para verificar metodologias pré-existentes de avaliação do geopatrimônio e na criação de uma ficha de avaliação/quantificação para identificar o potencial estético, científico, o uso potencial e a necessidade de proteção das geoformas. Como resultado realizou-se a avaliação de 15 geoformas, definindo-se aquelas que apresentam maior potencial estético para comporem roteiros turísticos na área do geoparque.

Palavras-chave: Geodiversidade, Turismo, Inventário.

\section{CONTEXTO DA PESQUISA}

A Terra é dinâmica e viva. Tudo o que está inserido nela decorre de uma transformação constante ao longo dos anos, seja de origem natural ou pelos intensos processos de desenvolvimento na sociedade, muitas vezes trazendo consequências negativas aos elementos naturais bióticos e abióticos. Quando nos referimos ao termo "biótico" logo associamos à biodiversidade, sendo esta considerada como a diversidade dos organismos vivos, porém quando nos referimos ao termo "abiótico" é comum observarmos que grande parte da população conceitua como fatores soltos (clima, relevo, entre outros), mas não com uma noção de conjunto, como ocorre na biodiversidade. Apesar de haver grandes debates e divulgações, o termo geodiversidade (conjunto dos elementos abióticos) difundido a partir da década de 1990, ainda precisa muito ser divulgado para atingir uma parte maior da população. 
A morfologia de um determinado ambiente (hidrografia, relevo e as comunidades bióticas), reflete-se na paisagem que, de acordo com Siqueira et al (2013), tanto nas ciências geográficas como na Ecologia é conceituada, de modo geral, como tudo o que o ser humano vê. Ainda considerando a Terra como um sistema dinâmico e os elementos abióticos e bióticos sofrendo alterações, decorrentes de processos de intemperismo ou ações antrópicas, é possível afirmar que as paisagens se modificam com o passar do tempo. Essas modificações, no caso do relevo, podem ocorrer desde a um bloco rochoso até serras e montanhas, que ao passarem por processos morfogenéticos tendem a perder sua morfologia original, dando origem a formas que muitas vezes se assemelham a imagens conhecidas (reação conhecida como pareidolia). Borba e Meneses (2013) conceituam essas semelhanças nas rochas como geoformas:

As formas percebidas nos elementos da geodiversidade e que por processos de associação, remetem o imaginário à imagens conhecidas como formas animais/humanas ou a pseudo vestígios (marcas de pegadas, por exemplo).

Vale ressaltar que o termo geoforma encontrado em diversas literaturas, tem conceito diferente do que é adotado nesta pesquisa. Na literatura das geociências lusófonas (Portugal), especialmente na ciência geomorfológica e geológica, o termo se refere às feições do relevo resultantes das ações do tempo e dos processos endógenos e exógenos na superfície terrestre (SILVA, 2008), ou seja, é um conceito muito próximo ou até mesmo semelhante ao de "forma de relevo". 
No Brasil, no entanto, esse termo não tem o emprego muito comum na literatura científica e quando utilizado, toma aplicabilidade bastante controversa e às vezes até divergente em alguns casos.

Aranha e Guerra (2014) afirmam que a geomorfologia tem sido cada vez mais aplicada ao planejamento da atividade turística, para que o meio físico seja mais bem aproveitado e não ocorram impactos ambientais negativos. O relevo é um dos principais elementos que atraem os turistas na escolha dos destinos das viagens de lazer. As geoformas são os principais atrativos turísticos em alguns destinos, a exemplo da Pedra da Galinha Choca (Quixadá - CE), Pedra da Taça e da Garrafa (Paraná - PR), o Pão de Açúcar (Rio de Janeiro - RJ), a Pedra da Boca (Paraíba PB). Neste último exemplo, Borba et al (2015) propuseram um roteiro de uso das geoformas no Parque Estadual da Pedra da Boca como forma de dinamizar o turismo ali praticado.

Destaca-se que as geoformas podem apresentar valores acessórios, além do puramente estético. Muitas delas encontram-se em locais que são representativos da história evolutiva da Terra ou, em muitos casos, estarem associadas a valores culturais como lendas, folclore ou até mesmo à sítios arqueológicos que contenham inscrições rupestres, por exemplo. Percebe-se, assim, que as geoformas, para além da apreciação estética, podem ser utilizadas como indutoras de visitação e, assim, ser possível transmitir aos visitantes, informações sobre as ciências da Terra, história, cultura e conservação do patrimônio natural e cultural. 
Com base no que foi exposto o presente trabalho teve como objetivo criar uma metodologia de inventário, que possa avaliar e classificar as geoformas que apresentam maior potencial estético para servirem de atrativo turístico e que possam ser úteis para de divulgar ao público o conhecimento sobre as geociências e em particular a geodiversidade, bem como contribuir para consolidar ainda mais o turismo na região e movimentar a economia dos municípios que compõem o território do Projeto Geoparque Cariri Paraibano (PGCP).

\section{ÁREA DE ESTUDO}

A área de estudo compreende os municípios de Cabaceiras, Boa Vista, São João do Cariri e Boqueirão, localizados na região conhecida como Cariris Velhos no estado da Paraíba (Figura 1), e que compõem o Geoparque Cariri Paraibano que está em fase de estudos pelo Serviço Geológico do Brasil (CPRM) e pelo Grupo de Estudos GeodiversidadePB - UFPB (NASCIMENTO et al, 2016).

Do ponto de vista geológico, a área encontra-se no contexto da Província Borborema, sendo composto basicamente por rochas magmáticas e metamórficas, dentre as quais se destacam os granitos, gnaisses, filitos, xistos e migmatitos (CARVALHO, 1982). As áreas sedimentares ali identificadas são representadas por capeamentos do Terciário e restringem-se basicamente à área da Bacia Sedimentar de Boa Vista. 


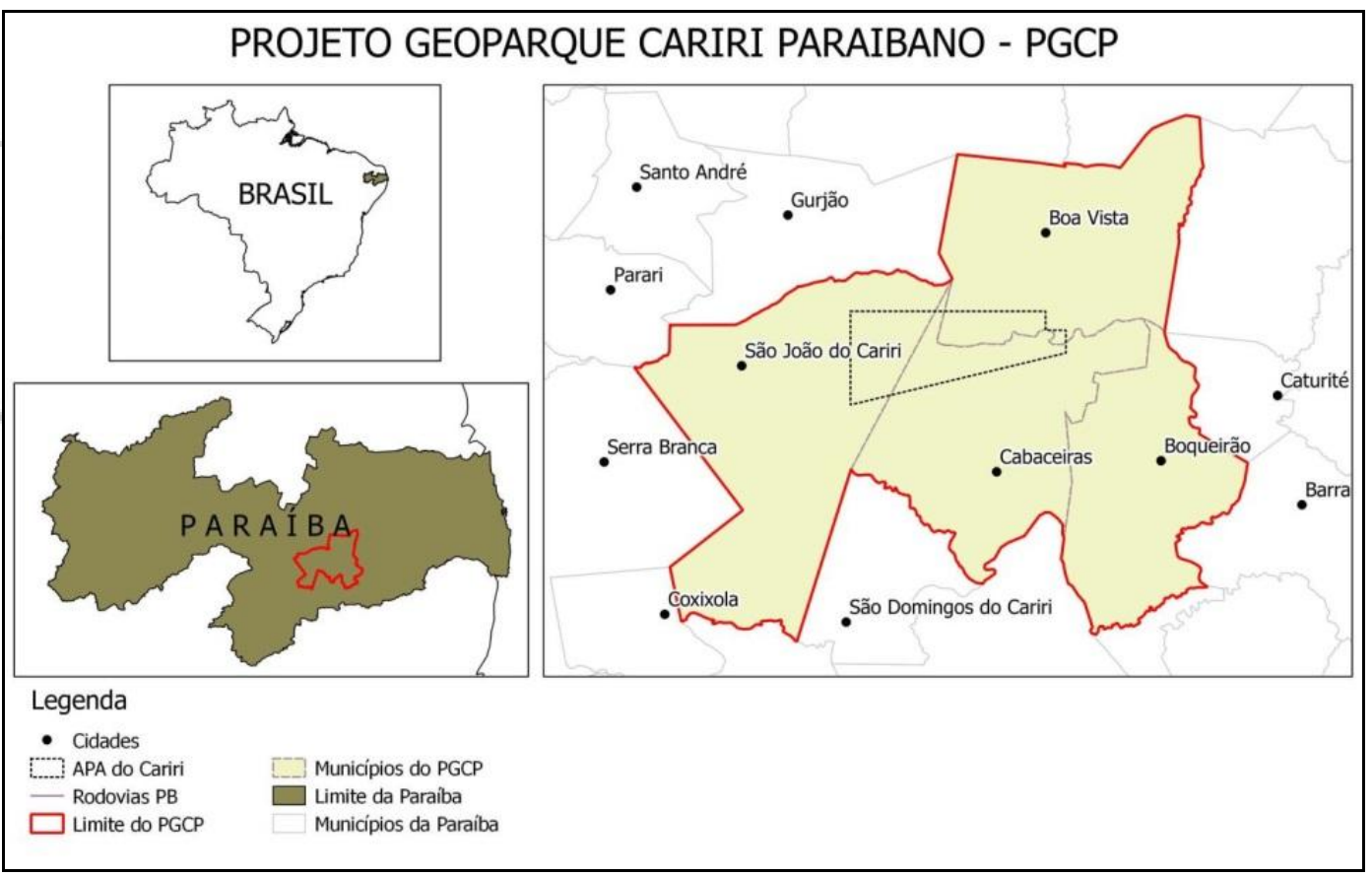

Figura 1: Localização da área de estudo. Fonte: Meneses e Souza (2017).

Quanto à geomorfologia, a área apresenta-se dividida em duas grandes unidades. A primeira é a Superfície Aplainada dos Cariris, que apresenta altitudes variando entre os 400 e 500 metros (CARVALHO, 1982) e relevo predominantemente plano, fruto dos processos denudacionais que atuam sobre a área ao longo do tempo geológico. A segunda unidade corresponde aos Maciços Residuais, em geral pouco extensos, que representam o testemunho de níveis altimétricos mais elevados ou, em alguns casos, exemplos do processo de granitização ocorrido ao longo do Pré-Cambriano naquela região, sendo compostos por serras e inselbergs, 
constituídos em sua grande maioria por granitoides e dioritos (CARVALHO, 1982).

O clima da região do Cariri é tipicamente semiárido caracterizado pelo baixo índice pluviométrico, de cerca de 400 a $500 \mathrm{~mm} /$ ano e as temperaturas médias são elevadas (cerca de $27^{\circ} \mathrm{C}$ ), ocasionando déficits hídricos acentuados (TRAVASSOS, 2012). Os solos são em sua maioria litólicos, rasos e, em muitos casos, com altos teores de salinidade, dificultando o desenvolvimento das atividades agropecuárias.

As condições edáficas e climáticas condicionam a vegetação que é predominantemente de caatinga hiperxerófila. O quadro natural (clima, vegetação, relevo e hidrografia) do Cariri, compromete o desenvolvimento de atividades econômicas, no entanto é uma região que o cenário de paisagens formadas pelos elementos da geodiversidade tem se mostrado com grande potencial para o desenvolvimento de atividades ligadas ao turismo e à cultura, o que pode ser trabalhado como forma alternativa de melhorar a economia da região.

A paisagem do Cariri possui uma alta representatividade de afloramentos rochosos, que chamam a atenção das pessoas para visitações caracterizando-se esses locais, portanto, como atrativos turísticos e que nas últimas décadas vem gerando um bom fluxo de turismo na região e, em especial nos municípios da área de estudo. Em épocas de festividades tradicionais, como por exemplo, a famosa 
festa do "Bode Rei" no município de Cabaceiras e a festa de Nossa Senhora dos Milagres em São João do Cariri, o fluxo de turistas aumenta consideravelmente, viabilizando o desenvolvimento de diversas atividades econômicas nesses municípios e gerando uma demanda bastante expressiva de pessoas que podem ser captadas para a visitação dos locais onde se encontram as geoformas.

\section{MATERIAIS E MÉTODOS}

A avaliação das geoformas foi realizada em duas etapas principais: a inventariação e a quantificação, divididas em cinco subetapas (Figura 2).

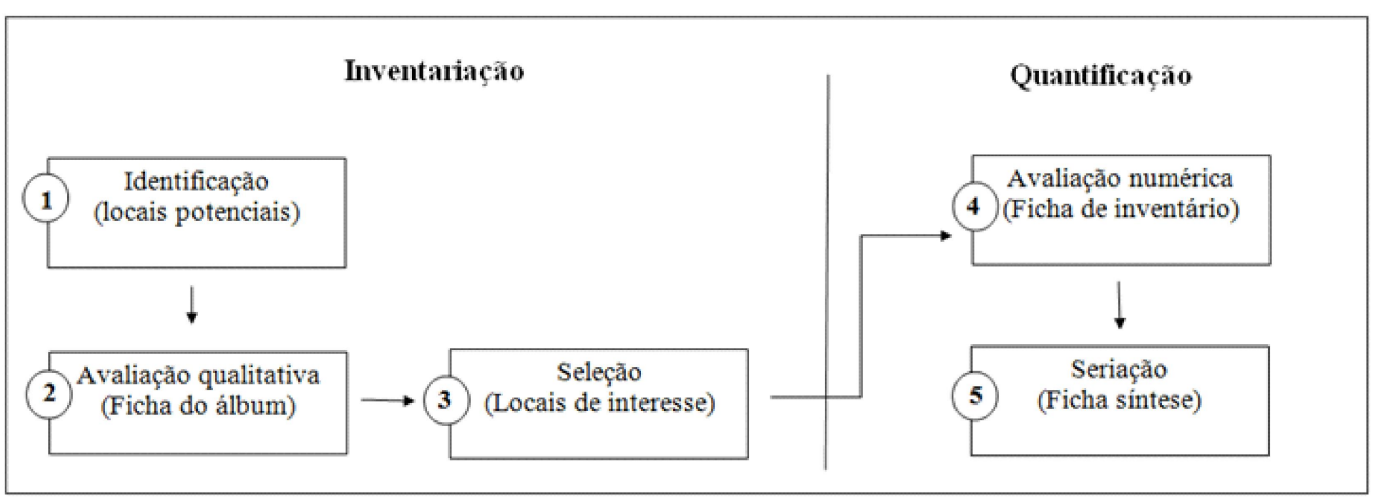

Figura 2: Etapas e subetapas para avaliação das geoformas no Cariri Paraibano.

\section{Inventariação}

A escolha das geoformas para aplicar a metodologia desenvolvida tomou como base o inventário apresentado em Borba (2016), das quais foram selecionadas 15 (quinze) geoformas para o presente estudo, distribuídas em 03 (três) dos 04 
(quatro) municípios do PGCP (São João do Cariri, Boa Vista e Cabaceiras). O município de Boqueirão também dispõe de geoformas, mas como elas não foram listadas no inventário de Borba (2016), essas geoformas não foram submetidas à presente avaliação.

Para avaliar as geoformas foi necessário realizar adaptações de metodologias préexistentes visando adequá-las às características particulares da área e do objeto em estudo. As principais referências utilizadas para a construção da metodologia proposta nesta pesquisa foram os trabalhos de Brilha (2005), Pereira (2006), Nascimento et al, (2008) e Bento e Rodrigues (2013).

Nesta etapa também foram executados trabalhos de campo visando levantar dados da área de estudo, possibilitando conhecer os locais onde cada geoforma está inserida, ao mesmo tempo em que foram preenchidas as fichas de quantificação elaboradas como um dos objetivos da pesquisa. As visitas de campo foram realizadas no período de 2014 a 2016 e foram utilizados equipamentos como: câmeras fotográficas para registro de paisagens (geoformas e entorno), receptores GPS para georeferenciamento da área e ficha de quantificação.

Uma vez realizada a seleção das geoformas, passou-se à fase de quantificação do potencial de cada uma delas com base nos dados obtidos na ficha de campo elaborada. 


\section{Quantificação}

Essa fase serviu para uma classificação quantitativa dos locais com melhor representatividade do potencial estético com base nas geoformas. A ficha de quantificação criada a partir da metodologia desenvolvida nessa pesquisa apresenta 05 grupos de dados, sendo o primeiro com dados gerais de identificação da geoforma, o segundo e o terceiro com critérios referentes ao potencial estético e ao científico, respectivamente. Este último, inclusive possibilitando a indicação da existência de sítios arqueológicos no próprio afloramento onde se observa a geoforma ou em seu entorno.

O quarto caracteriza o uso potencial e o quinto, a necessidade de proteção do local, em um total de 21 parâmetros (Figura 3). Cada um dos parâmetros apresentam opções que podem receber entre 0 e 3 pontos, sendo que quanto maior o valor obtido no critério, melhor será o desempenho do local inventariado no referido item.

O Quadro 01 apresenta as descrições (metadados) de cada parâmetro do potencial estético, do científico, do uso potencial e da necessidade de proteção.

Para cada geoforma foi preenchida uma ficha para contabilizar o valor que cada local de interesse recebeu, o que tornou possível depois compará-las entre si, estabelecendo um ranking. Com base nas informações presentes nas fichas, as geoformas foram avaliadas pela aplicação da Equação 1. 


\section{Potencial Estético $=\underline{4 A+3 B+C+2 D}$}

(Equação 1)

Onde: A - potencial estético; B - potencial científico; C - uso potencial; D necessidade de proteção
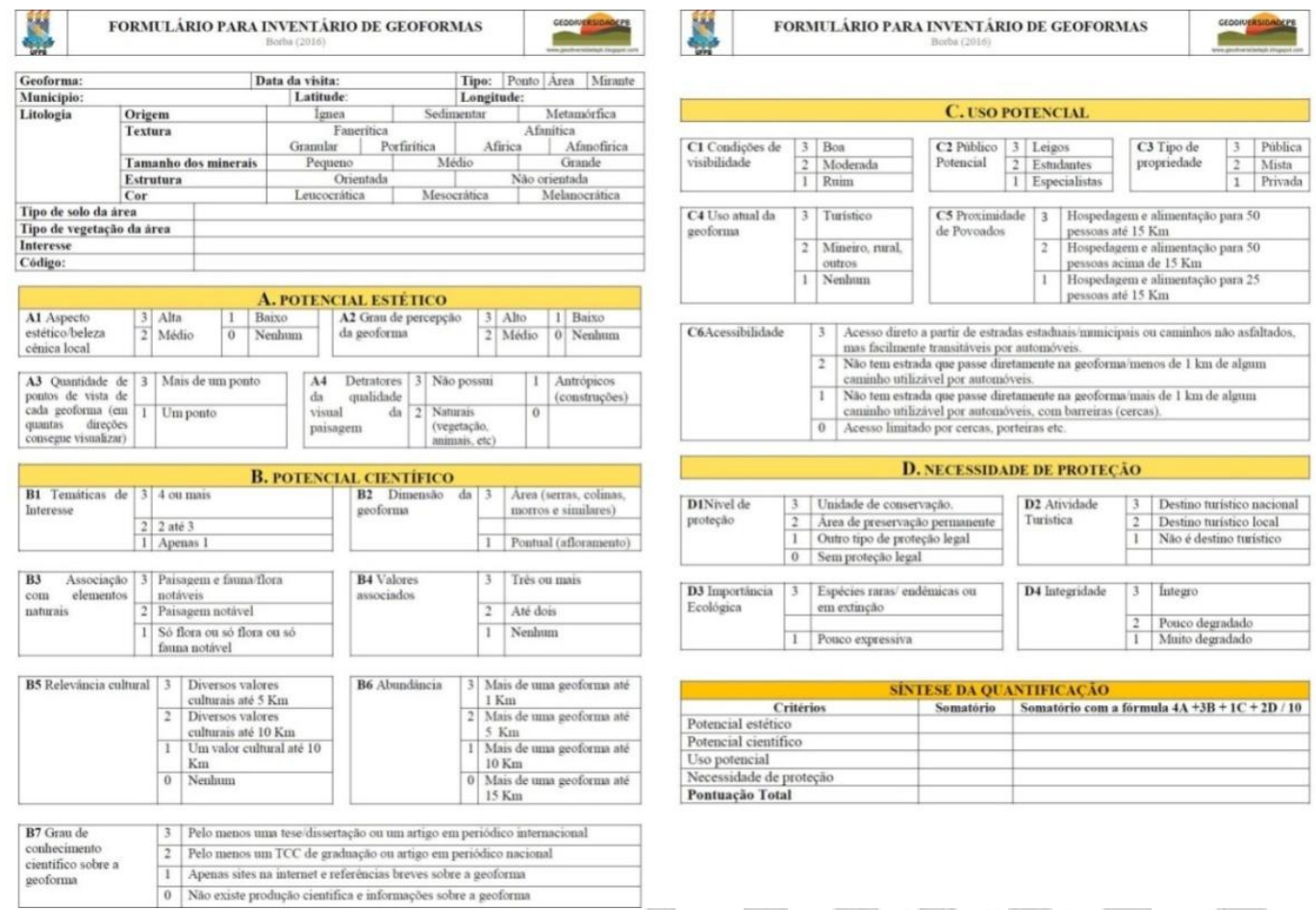

Figura 3: Ficha de Campo para quantificação. 


\begin{tabular}{|c|c|}
\hline A. Potencial Estético & Descrição \\
\hline A1) Aspecto estético / beleza cênica local & Aspecto do conjunto da paisagem onde se insere a geoforma. \\
\hline A2) Grau de percepção da geoforma & Facilidade para perceber uma pareidolia no afloramento/relevo. \\
\hline $\begin{array}{l}\text { A3) Quantidade de pontos de vista da } \\
\text { geoforma }\end{array}$ & Em quantas direções é possível visualizar a geoforma. \\
\hline $\begin{array}{l}\text { A4) Detratores da qualidade visual da } \\
\text { paisagem }\end{array}$ & $\begin{array}{l}\begin{array}{l}\text { Presença de elementos estranhos à paisagem e que lhe } \\
\text { perturbam a estética (construções, etc). }\end{array} \\
\end{array}$ \\
\hline B. Potencial Científico & Descrição \\
\hline B1) Temáticas de Interesse & $\begin{array}{l}\text { Temáticas da geologia que podem ser trabalhadas e/ou } \\
\text { estudadas na geoforma (geomorfologia, mineralogia, } \\
\text { petrografia, paleontologia). }\end{array}$ \\
\hline B2) Dimensão da geoforma & Tamanho da geoforma. \\
\hline B3) Associação com elementos naturais & $\begin{array}{l}\text { Ocorrência de exemplos particulares da biodiversidade (fauna e } \\
\text { /ou flora). }\end{array}$ \\
\hline B4) Valores associados & $\begin{array}{l}\text { Valores da geodiversidade de acordo com Gray (2004): } \\
\text { intrínseco, estético, cultural, econômico, cientifico/didático, } \\
\text { funcional. }\end{array}$ \\
\hline B5) Relevância cultural & $\begin{array}{l}\text { Presença de ocorrências consideradas patrimônio cultural } \\
\text { (evidências arqueológicas, históricas, artísticas, etc) ou natural } \\
\text { (evidências paleontológicas). }\end{array}$ \\
\hline B6) Abundância & Proximidade entre geoformas \\
\hline $\begin{array}{l}\text { B7) Grau de conhecimento científico sobre } \\
\text { a geoforma }\end{array}$ & $\begin{array}{l}\text { Divulgação da geoforma, ou do sítio onde se insere, em meios } \\
\text { técnico-científicos (TCC, dissertações, teses, artigos, etc). }\end{array}$ \\
\hline C. Uso Potencial & Descrição \\
\hline C1) Condições de visibilidade & $\begin{array}{l}\text { Inexistência de obstáculos que atrapalhem a observação da } \\
\text { geoforma. }\end{array}$ \\
\hline C2) Público potencial & Perfil esperado dos potenciais visitantes. \\
\hline C3) Tipo de propriedade & Regime da propriedade quanto a público e privado. \\
\hline C4) Uso atual da área & $\begin{array}{l}\text { Quais atividades se desenvolvem atualmente na área onde está } \\
\text { a geoforma. }\end{array}$ \\
\hline C5) Proximidade de povoados & $\begin{array}{l}\text { Está relacionada com a existência de serviços de apoio aos } \\
\text { visitantes dos geossítios. }\end{array}$ \\
\hline C6) Acessibilidade & $\begin{array}{l}\text { Considera-se como situação favorável a possibilidade de acesso } \\
\text { fácil ao geossítio. }\end{array}$ \\
\hline D. Necessidade de Proteção & Descrição \\
\hline D1) Nível de proteção & $\begin{array}{l}\text { Existência de algum dispositivo legal de proteção da área (UC, } \\
\text { APP, outra). }\end{array}$ \\
\hline D2) Atividade turística & Ocorrência de atividade turística já consolidada no local. \\
\hline D3) Importância ecológica & $\begin{array}{l}\text { Relacionado com a conservação de espécies no lugar,se } \\
\text { estãoem extinção ou endêmicas. }\end{array}$ \\
\hline D4) Integridade & Condições físicas que se encontra a geoforma. \\
\hline
\end{tabular}

Quadro 1: Metadados dos critérios para quantificar o valor estético, de uso e de proteção das geoformas. 
O Potencial Estético recebe maior peso (4) por ser o critério fundamental a pesquisa já que se trata da estética da geoforma. Os valores referentes ao Potencial Científico recebem peso 3 por ser o critério de relevância científica e didática da geoforma. O critério Uso Potencial recebe peso 1 e o critério relacionado com a Necessidade de Proteção recebe peso 2, pois se a geoforma apresentar um alto índice de degradação, para executar o turismo nela será necessária antes a adoção de algumas medidas preventivas entre elas um estudo de capacidade de carga, para não piorar o seu estado de conservação.

A última fase foi, portanto, estabelecer o ranking das geoformas a partir da pontuação final que cada uma delas obteve. Considerou-se que, aquelas que obtiveram pontuação final igual ou superior à média de todas as geoformas, correspondem às mais favoráveis à percepção e uso e que encontram-se em melhor estado de conservação, enquanto as que se apresentam abaixo da média são as de menor percepção do ponto de vista da pareidolia ou apresentam algum tipo de restrição de uso ou de conservação.

\section{RESULTADOS E DISCUSSÕES:}

Como referido anteriormente, ao todo foram avaliadas 15 (quinze) geoformas, as quais encontram-se listadas no Quadro 2, juntamente com a codificação que lhes foi atribuída e suas coordenadas geográficas. 


\begin{tabular}{|c|c|c|c|c|}
\hline \multirow{2}{*}{ Nome da Geoforma } & \multirow{2}{*}{ Município } & \multirow{2}{*}{ Código } & \multicolumn{2}{|c|}{ Coordenadas } \\
\cline { 4 - 5 } & & Latitude & Longitude \\
\hline Pedra do Caju & Boa Vista & Bv01 & $-7,36046^{\circ}$ & $-36,2461^{\circ}$ \\
\hline Pedra da Vagina & Boa Vista & Bv02 & $-7,36026^{\circ}$ & $-36,2462^{\circ}$ \\
\hline Pedra da Formiga & Boa Vista & Bv03 & $-7,35922^{\circ}$ & $-36,2469^{\circ}$ \\
\hline Pedra do Urso & Boa Vista & Bv04 & $-7,3579^{\circ}$ & $-36,2471^{\circ}$ \\
\hline Muralha do Cariri & Boa Vista & Bv05 & $-7,36281^{\circ}$ & $-36,2525^{\circ}$ \\
\hline Saca de Lã & Cabaceiras & Cab01 & $-7,374931^{\circ}$ & $-36,323298^{\circ}$ \\
\hline Pedra da Baleia & Cabaceiras & Cab02 & $-7,381^{\circ}$ & $-36,2966^{\circ}$ \\
\hline Pedra da Orelha & Cabaceiras & Cab03 & $-7,38202^{\circ}$ & $-36,2979^{\circ}$ \\
\hline Pedra do Capacete & Cabaceiras & Cab04 & $-7,38116^{\circ}$ & $-36,2967^{\circ}$ \\
\hline Pedra do Sapo & Cabaceiras & Cab05 & $-7,38065^{\circ}$ & $-36,2979^{\circ}$ \\
\hline Pedra da Pata & Cabaceiras & Cab06 & $-7,5541^{\circ}$ & $-36,2737^{\circ}$ \\
\hline Pedra da Tartaruga de Pente & São João do Cariri & Sjc01 & $-7,4315^{\circ}$ & $-36,569^{\circ}$ \\
\hline Muralha do Meio do Mundo & São João do Cariri & Sjc02 & $-7,43527^{\circ}$ & $-36,5673^{\circ}$ \\
\hline Pedra do Lagarto & São João do Cariri & Sjc03 & $-7,43602^{\circ}$ & $-36,5671^{\circ}$ \\
\hline Pedra do Leão & São João do Cariri & Sjc04 & $-7,43602^{\circ}$ & $-36,5671^{\circ}$ \\
\hline
\end{tabular}

Quadro 2: Geoformas Inventariadas.

Com base na aplicação das fichas de quantificação para as geoformas, foram definidas as pontuações de cada conjunto de critérios e o valor final de seu potencial estético. A Tabela 1 apresenta em detalhes os valores para cada parâmetro avaliado, enquanto que a Tabela 2 apresenta uma síntese dos resultados, dando destaque para os locais que obtiveram pontuação final acima da média, que foi 10,6. As Figuras 4 e 5 ilustram as geoformas melhor ranqueadas.

Considerou-se como geoformas mais expressivas aquelas cuja pontuação final na quantificação ficaram acima da média da pontuação das geoformas inventariadas. Uma vez que a média obtida foi de 10,6 pontos, observa-se que 8 (oito) geoformas encontram-se acima desse valor (Muralha do Cariri, Muralha do Meio do Mundo, 
Pedra da Baleia, Pedra da Orelha, Pedra da Vagina, Pedra do Capacete, Pedra do Sapo e a Saca de Lã).

Nas posições abaixo da média ficaram quase que totalmente as geoformas que foram “descobertas" nas etapas de campo da pesquisa, à exceção da Pedra da Pata. Ainda que tenham ficado abaixo da média na pontuação final, estas geoformas também devem ser divulgadas e podem ser incluídas nos roteiros turísticos que envolvam aquelas melhor classificadas, uma vez que muitas delas ficam localizadas a poucos metros daquelas de maior pontuação ou nos trajetos de acesso. A Figura 6 apresenta o gráfico com a classificação das geoformas para o potencial estético, o científico, uso potencial e a necessidade de proteção. A Figura 7 apresenta de forma gráfica esse resultado geral. 


\begin{tabular}{|c|c|c|c|c|c|c|c|c|c|c|c|c|c|c|c|}
\hline & $\begin{array}{l}\text { Bv } \\
01\end{array}$ & $\begin{array}{l}\text { Bv } \\
02 \\
\end{array}$ & $\begin{array}{l}\text { Bv } \\
\mathbf{0 3} \\
\end{array}$ & $\begin{array}{l}\text { Bv } \\
04 \\
\end{array}$ & $\begin{array}{l}\text { Bv } \\
05 \\
\end{array}$ & \begin{tabular}{|c|} 
Cab \\
01 \\
\end{tabular} & $\begin{array}{c}\text { Cab } \\
02 \\
\end{array}$ & $\begin{array}{c}\text { Cab } \\
03 \\
\end{array}$ & $\begin{array}{c}\text { Cab } \\
04 \\
\end{array}$ & $\begin{array}{c}\text { Cab } \\
05 \\
\end{array}$ & $\begin{array}{c}\text { Cab } \\
06 \\
\end{array}$ & $\begin{array}{c}\text { Sjc } \\
01 \\
\end{array}$ & $\begin{array}{l}\text { Sjc } \\
02\end{array}$ & $\begin{array}{l}\text { Sjc } \\
\mathbf{0 3} \\
\end{array}$ & $\begin{array}{l}\text { Sjc } \\
04\end{array}$ \\
\hline \multicolumn{16}{|c|}{ POTENCIAL ESTÉTICO } \\
\hline A1 & 2 & 2 & 2 & 1 & 2 & 2 & 3 & 3 & 3 & 3 & 3 & 1 & 2 & 2 & 2 \\
\hline A2 & 1 & 1 & 2 & 2 & 3 & 2 & 2 & 3 & 3 & 2 & 3 & 3 & 3 & 3 & 3 \\
\hline A3 & 3 & 1 & 1 & 1 & 1 & 1 & 1 & 3 & 3 & 1 & 1 & 1 & 3 & 1 & 1 \\
\hline A4 & 3 & 3 & 2 & 3 & 3 & 3 & 3 & 3 & 3 & 3 & 3 & 2 & 3 & 3 & 2 \\
\hline Total & 9 & 7 & 7 & 7 & 9 & 8 & 9 & 12 & 12 & 9 & 10 & 7 & 11 & 9 & 8 \\
\hline \multicolumn{16}{|c|}{ POTENCIAL CIENTÍFICO } \\
\hline B1 & 2 & 2 & 2 & 2 & 2 & 2 & 2 & 2 & 2 & 2 & 2 & 2 & 2 & 2 & 2 \\
\hline $\mathrm{B} 2$ & 1 & 1 & 1 & 1 & 1 & 1 & 1 & 1 & 1 & 1 & 1 & 1 & 1 & 1 & 1 \\
\hline B3 & 2 & 3 & 2 & 1 & 2 & 2 & 2 & 3 & 2 & 2 & 3 & 1 & 1 & 1 & 1 \\
\hline B4 & 3 & 3 & 2 & 3 & 2 & 3 & 3 & 3 & 3 & 3 & 3 & 3 & 2 & 3 & 3 \\
\hline B5 & 3 & 3 & 3 & 3 & 3 & 3 & 3 & 3 & 3 & 3 & 0 & 3 & 3 & 3 & 3 \\
\hline B6 & 3 & 3 & 3 & 3 & 3 & 2 & 3 & 3 & 3 & 3 & 0 & 3 & 3 & 3 & 3 \\
\hline B7 & 0 & 1 & 0 & 0 & 1 & 3 & 0 & 0 & 3 & 0 & 2 & 0 & 1 & 0 & 0 \\
\hline Total & 14 & 16 & 13 & 13 & 14 & 16 & 14 & 15 & 17 & 14 & 11 & 13 & 13 & 13 & 13 \\
\hline \multicolumn{16}{|c|}{ USO POTENCIAL } \\
\hline $\mathrm{C} 1$ & 3 & 3 & 3 & 3 & 3 & 3 & 3 & 3 & 3 & 3 & 3 & 2 & 3 & 3 & 3 \\
\hline $\mathrm{C} 2$ & 2 & 2 & 2 & 2 & 3 & 1 & 1 & 1 & 1 & 1 & 3 & 3 & 2 & 1 & 1 \\
\hline C3 & 1 & 1 & 1 & 1 & 1 & 1 & 1 & 1 & 1 & 1 & 1 & 1 & 1 & 1 & 1 \\
\hline $\mathrm{C} 4$ & 1 & 3 & 3 & 1 & 3 & 3 & 1 & 1 & 3 & 1 & 1 & 1 & 3 & 1 & 1 \\
\hline $\mathrm{C} 5$ & 3 & 3 & 3 & 3 & 3 & 3 & 3 & 3 & 3 & 3 & 2 & 3 & 3 & 3 & 3 \\
\hline C6 & 2 & 2 & 2 & 2 & 1 & 2 & 2 & 2 & 2 & 2 & 2 & 3 & 3 & 3 & 3 \\
\hline Total & 12 & 14 & 14 & 12 & 14 & 13 & 11 & 11 & 13 & 11 & 12 & 13 & 15 & 12 & 12 \\
\hline \multicolumn{16}{|c|}{ NECESSIDADE DE PROTEÇÃO } \\
\hline D1 & 3 & 3 & 3 & 3 & 3 & 3 & 3 & 3 & 3 & 3 & 0 & 0 & 0 & 0 & 0 \\
\hline D2 & 1 & 2 & 3 & 1 & 2 & 3 & 3 & 3 & 3 & 3 & 2 & 1 & 3 & 1 & 1 \\
\hline D3 & 1 & 1 & 1 & 1 & 1 & 1 & 1 & 1 & 1 & 1 & 1 & 1 & 1 & 1 & 1 \\
\hline D4 & 2 & 3 & 3 & 3 & 3 & 3 & 3 & 3 & 3 & 3 & 3 & 3 & 3 & 3 & 3 \\
\hline Total & 7 & 9 & 10 & 8 & 9 & 10 & 10 & 10 & 10 & 10 & 6 & 5 & 7 & 5 & 5 \\
\hline $\begin{array}{c}\text { Pont } \\
\text { ua- } \\
\text { ção } \\
\text { final }\end{array}$ & $\begin{array}{c}10 \\
4\end{array}$ & $\begin{array}{c}10 \\
8\end{array}$ & $\begin{array}{c}10 \\
1\end{array}$ & 9,5 & 11 & 11,3 & 10,9 & 12,4 & 13,2 & 10,9 & 9,7 & 9,0 & $\begin{array}{c}11, \\
2\end{array}$ & 9,7 & 9,3 \\
\hline
\end{tabular}

Tabela 1: Resultados de cada valor da ficha de quantificação das geoformas. 
Clio Arqueológica 2017, V32N3, p.37-60, BORBA; MENESES.

DOI: 10.20891/clio.V32N3p37-60

\begin{tabular}{|c|c|c|c|c|c|c|c|}
\hline \multirow[t]{2}{*}{ Ranking } & \multirow[t]{2}{*}{ Código } & \multirow[t]{2}{*}{ Geoformas } & \multicolumn{4}{|c|}{ Critérios } & \multirow{2}{*}{$\begin{array}{c}\text { Pontuação } \\
\text { Final }\end{array}$} \\
\hline & & & $\mathbf{A}$ & B & $\mathbf{C}$ & D & \\
\hline $1^{\circ}$ & Cab04 & Pedra do Capacete & 12 & 17 & 13 & 10 & 13,2 \\
\hline $2^{\circ}$ & Cab03 & Pedra da Orelha & 12 & 15 & 11 & 10 & 12,4 \\
\hline $3^{\circ}$ & Cab01 & Saca de Lã & 8 & 16 & 13 & 10 & 11,3 \\
\hline $4^{\circ}$ & Sjc02 & Muralha do Meio do Mundo & 9 & 13 & 15 & 7 & 11,2 \\
\hline $5^{\circ}$ & $\mathrm{Bv} 05$ & Muralha do Cariri & 9 & 14 & 14 & 9 & 11 \\
\hline $6^{\circ}$ & Cab05 & Pedra do Sapo & 9 & 14 & 11 & 10 & 10,9 \\
\hline $7^{\circ}$ & Cab02 & Pedra da Baleia & 9 & 14 & 11 & 10 & 10.9 \\
\hline $8^{\circ}$ & Bv02 & Pedra da Vagina & 7 & 16 & 14 & 9 & 10,8 \\
\hline $9^{\circ}$ & Bv01 & Pedra do Caju & 9 & 14 & 12 & 7 & 10,4 \\
\hline $10^{\circ}$ & Bv03 & Pedra da Formiga & 7 & 13 & 14 & 10 & 10,1 \\
\hline $11^{\circ}$ & Cab06 & Pedrada Pata & 10 & 11 & 12 & 6 & 9,7 \\
\hline $12^{\circ}$ & Sjc03 & Pedra do Lagarto & 9 & 13 & 12 & 5 & 9,7 \\
\hline $13^{\circ}$ & Bv04 & Pedra do Urso & 7 & 13 & 12 & 8 & 9,5 \\
\hline $14^{\circ}$ & Sjc04 & Pedra do Leão & 8 & 13 & 12 & 5 & 9,3 \\
\hline $15^{\circ}$ & Sjc01 & Pedra da Tartaruga de Pente & 7 & 13 & 13 & 5 & 9 \\
\hline
\end{tabular}

Tabela 2: Valores finais e as geoformas classificadas acima da média em destaque no item pontuação final.
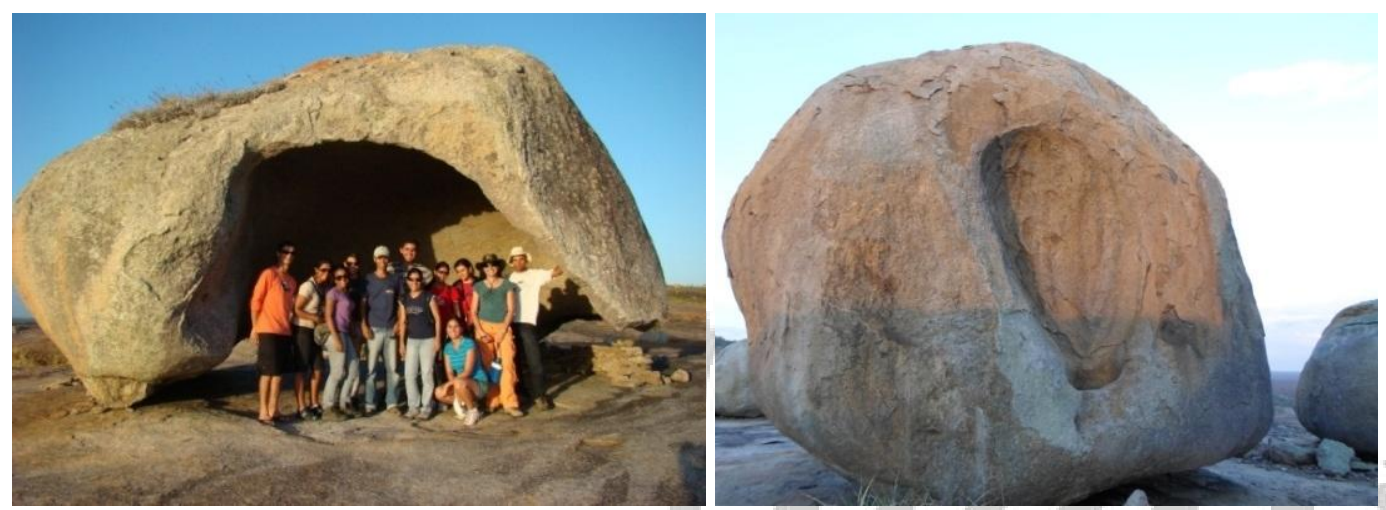

Figura 4: Pedra do Capacete e Pedra da Orelha, no município de Cabaceiras. 

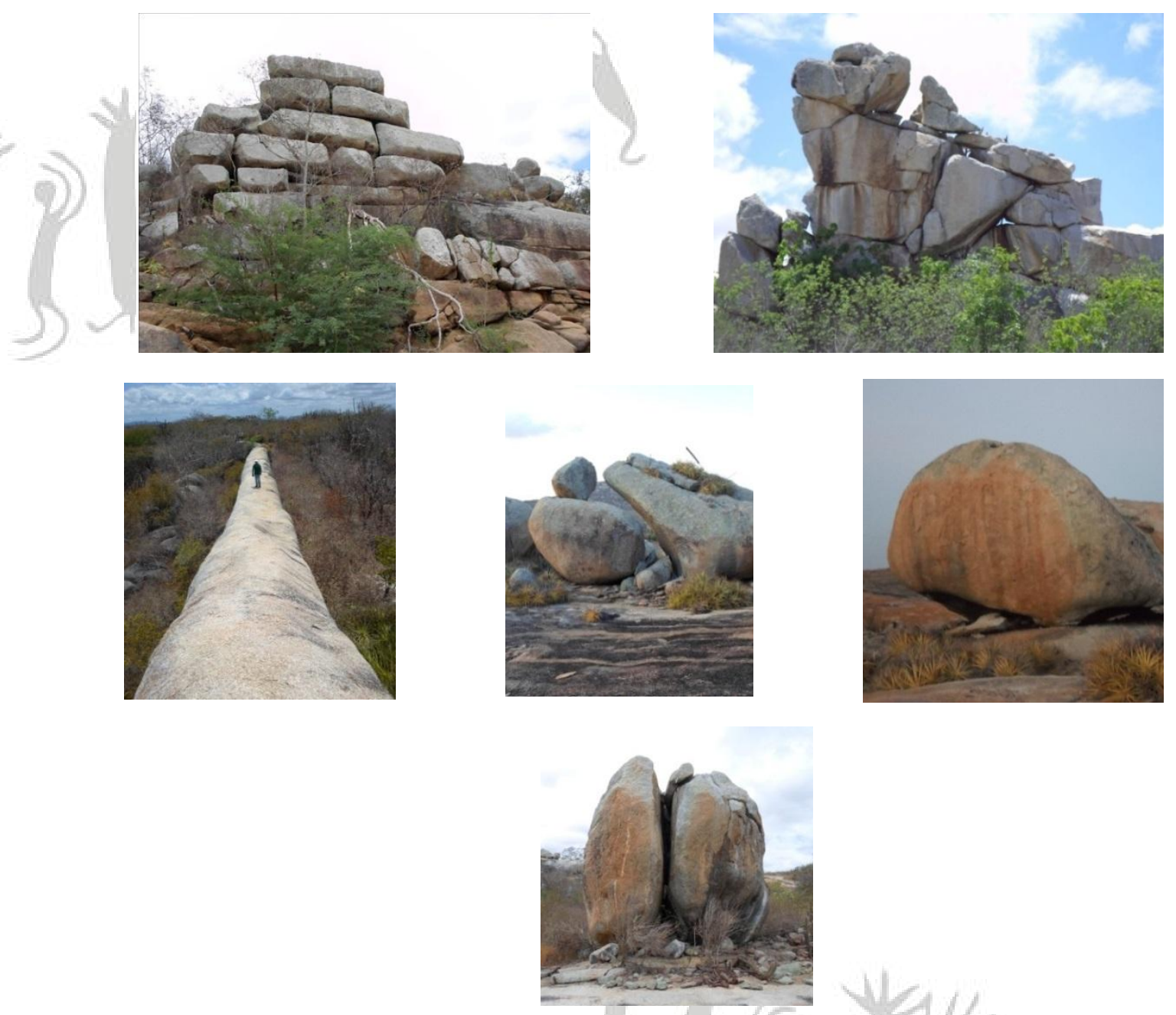

Figura 5: Geoformas Sacas de Lã, Muralha do Meio do Mundo, Muralha do Cariri, Pedra do Sapo, Pedra da Baleia e Pedra da Vagina.

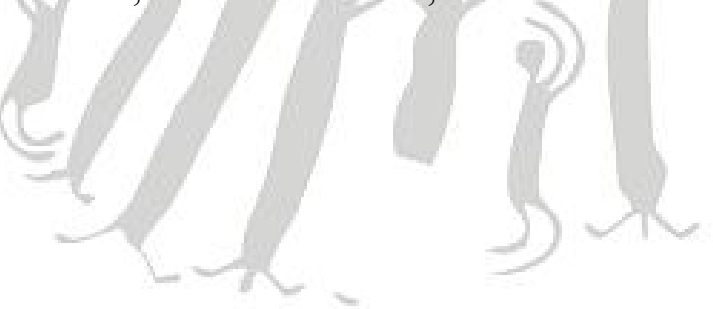




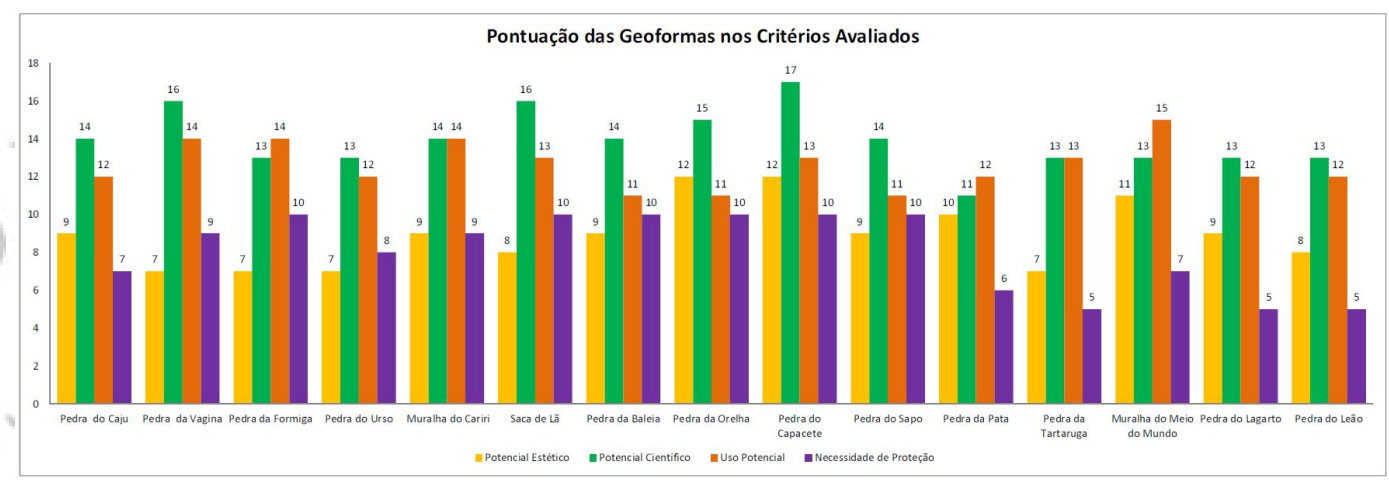

Figura 6: Ranking do potencial estético.

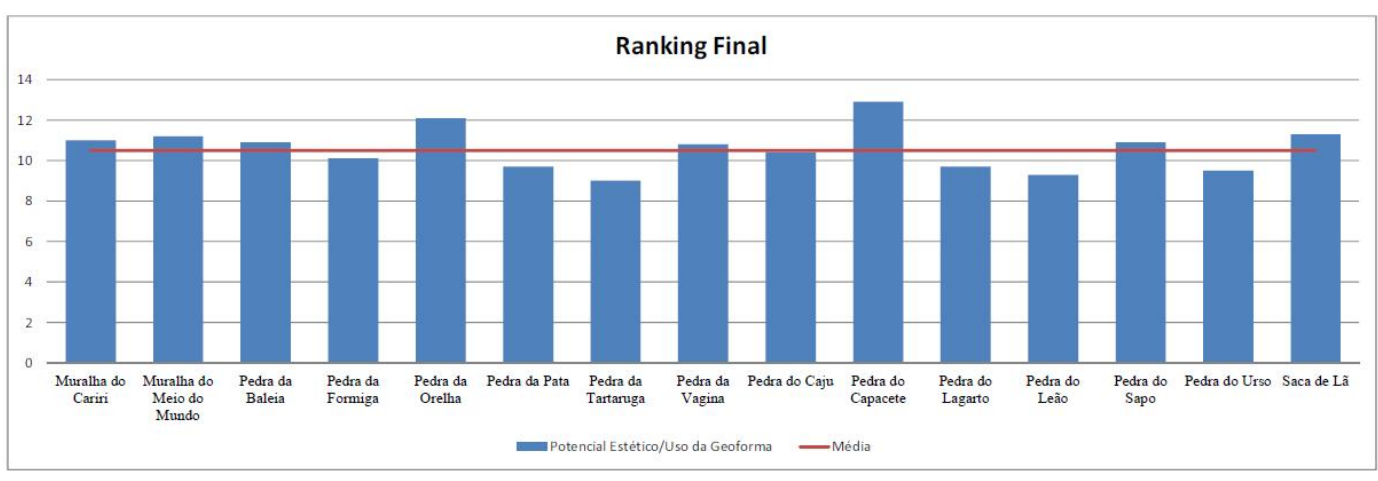

Figura 7: Ranking final das Geoformas.

A riqueza do potencial estético da geodiversidade dos municípios da área de estudo foi notadamente demonstrada ao longo de toda experiência de campo e da metodologia aplicada. Do ponto de vista do valor científico, as geoformas enquadram-se como sítios de geodiversidade, uma vez que obtiveram pontuações pouco expressivas nesse critério (exceto as geoformas inseridas no Lajedo de Pai Mateus), mas existindo em todos os casos associações com diversos valores da 
geodiversidade (cultural, estético, educativo), a exemplo dos sítios arqueológicos com pinturas rupestres e gravuras.

Todas as geoformas estudadas se desenvolvem em rochas graníticas, sendo que a Pedra da Pata, do Capacete, do Sapo, da Orelha, da Baleia, da Formiga, do Caju, da Vagina e do Urso constituem matacões de dimensões métricas a decamétricas, enquanto que a Muralha do Cariri, Muralha do Meio do Mundo, Pedra do Leão e Pedra do Lagarto encontram-se sob a forma de diques.

As oito geoformas que ficaram em melhor classificação (acima da média) correspondem basicamente à locais que já estão consolidados do ponto de vista turístico e/ou científico e são famosas na região pela beleza de suas estruturas e tratam-se de locais que possuem excelente visibilidade, boa acessibilidade e baixa vulnerabilidade.

No contexto geral, as geoformas Pedra do Capacete, Pedra da Orelha, Sacas de Lã e a Muralha do Meio do Mundo se destacaram nas primeiras colocações, pois representam os locais em que ocorrea prática consolidada do turismo; apresentam um potencial de uso elevado, pois nesses locais podem se desenvolver diversas atividades além do turismo; e enquadram-se em um nível de proteção legal significativo por estarem dentro da APA do Cariri Paraibano. 
No critério Potencial Estético, as geoformas Pedra da Formiga, do Urso, da Vagina, da Tartaruga de Pente e do Leão apresentaram-se abaixo da média, motivada por terem recebido valores mais baixos nos fatores de aspecto estético/beleza cênica local e percepção da geoforma.

No critério Potencial Científico a maioria das geoformas ficou na média ou bem próximo à média. A Pedra da Pata foi a única a apresentar uma diferença significativa, levando desvantagem nos parâmetros "proximidade de outras geoformas" e "relevância cultural".

No caso do Uso Potencial, as geoformas apresentaram pouca variação, por estarem todas inseridas em áreas com mesmas características com relação a bioma, acessibilidade, tipo de propriedade e o uso turístico. Já no critério Necessidade de Proteção, as geoformas que ficaram abaixo da média correspondem àquelas que estão fora da área da APA do Cariri paraibano, à exceção da Pedra do Caju que ficou abaixo da média mesmo estando inserida na APA, porém apresenta degradações em sua estrutura devido ao intemperismo físico, típico da região de estudo. Vale ressaltar a importância da geoconservação, por exemplo, evitando o contato e extração de partes dela, para que a forma não seja destruída, acarretando na perda do atrativo turístico.

No que se refere à associação com sítios arqueológicos, observou-se que a geoforma da Muralha do Meio do Mundo conta com um painel com pinturas 
rupestres no próprio afloramento (Figura 8), sendo um dos sítios mais visitados na área. Em todas as demais geoformas, é possível encontrar sítios com pinturas ou gravuras em distâncias não superiores a 350 metros das geoformas. As únicas exceções são as geoformas da Pedra da Pata e a Muralha do Cariri, onde não foram observados sítios arqueológicos nem em seus entornos.
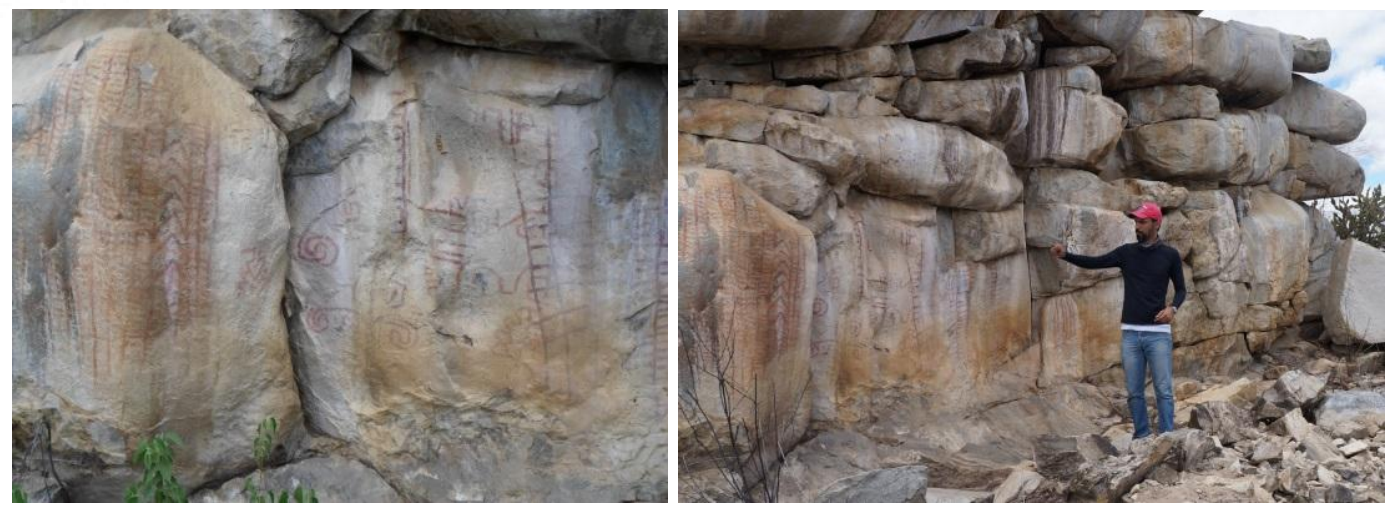

Figura 8: Pinturas rupestres na Muralha do Meio do Mundo. Fotos: Acervo pessoal dos autores

Por fim, ressalta-se que as geoformas não permitem aos turistas apenas contemplar a paisagem natural, mas ao visitá-las pode-se despertar a curiosidade sobre o passado do homem e outras culturas, possibilitando o conhecimento sobre os sítios arqueológicos de modo a apresentar aos turistas o passado remoto do ser humano, abordando a simbologia dos povos pretéritos, buscando a compreensão sobre a interação de culturas antigas com o meio natural e a preservação destes sítios. 


\section{REFERÊNCIAS BIBLIOGRÁFICAS}

ARANHA, R; C. GUERRA, A; J; T. Geografia Aplicada ao Turismo. São Paulo. Oficina de Textos, 2014.

BENTO, L. C. M; RODRIGUES; C. S. Seleção de geossítios para uso turístico no Parque Estadual do Ibitipoca/MG (PEI): uma proposta a partir de metodologias de avaliação numérica. Investigaciones Geográficas, Boletín, núm. 85, Instituto de Geografía, UNAM, México, p. 33-46, 2014.

BORBA, C. S. Geoformas: Potencial Estético para Uso Turístico na Área do Projeto Geoparque Cariri Paraibano. Monografia (graduação em Ecologia), Universidade Federal da Paraíba, Rio-Tinto, 2016.

BORBA, C. S.; MENESES, L. F. O potencial estético das geoformas do Cariri paraibano. In: Encontro Paraibano de Estudos sobre Geodiversidade, 2013, João Pessoa. Anais ... I Encontro Paraibano de Estudos sobre Geodiversidade, 2013.

BORBA, C. S.; MENESES, L. F.; CAVALCANTE, M. B. Pedra da Boca: O parque dos gigantes. Anais ... XVI Simpósio Brasileiro de Geografia Física Aplicada. Teresina Piauí. 2015.

BRILHA, J.B.R. Patrimônio Geológico e Geoconservação: a conservação da natureza na sua vertente geológica. Palimage Editora, 190p. 2005.

CARVALHO, M.G.R.F. Estado da Paraíba: classificação geomorfológica. Editora da UFPB. 67p. 1982.

MENESES, L.F.; SOUZA, B. I. Patrimônio Geomorfológico da Área do Projeto Geoparque Cariri Paraibano. In: LISTO, F.L.R; MÜTZENBERG, D.S; TAVARES, B.A.C. (Org.). I Workshop de Geomorfologia e Geoarqueologia do Nordeste. 1ed. Recife: GEQUA, 2017, v. 1, p. 67-77.

NASCIMENTO, M. A. L.; MENESES, L. F.; FERREIRA, R. V.; LAGES, G. A.; FIALHO, D. A. Projeto Geoparque Cariri Paraibano, Nordeste do Brasil In: Congresso Brasileiro de Geologia, 2016, Porto Alegre. $48^{\circ}$ Congresso Brasileiro de Geologia - as geotecnologias e o século XXI. , 2016. 
NASCIMENTO, M. A. L.; RUCHKYS, U. A.; MANTESSO-NETO, V. Geodiversidade, Geoconservação e Geoturismo: trinômio importante para a proteção do patrimônio geológico. São Paulo: Sociedade Brasileira 'de Geologia, 2008. p. 37.

PEREIRA, P.J. S. Patrimônio geomorfológico: conceitualização, avaliação e divulgação. Aplicação ao Parque Natural de Montesinho. Tese de Doutoramento, Universidade do Minho, Braga, 2006.

SILVA, C. R. Geodiversidade do Brasil: conhecer o passado, para entender o presente e prever o futuro. Rio de Janeiro: CPRM, 2008; p., 151.

SIQUEIRA, M. N; CASTRO. S. S; FARIA. K. M. S. Geografia e Ecologia DA Paisagem: Pontos para Discussão. Uberlândia, 2013.

TRAVASSOS, I. S. Florestas Brancas do Semiárido Nordestino: desmatamento e desertificação no Cariri Paraibano. Universidade Federal da Paraíba, João Pessoa, Dissertação, 2012. 